\title{
Sociologias Emergentes: uma agenda não-exemplar
}

\author{
Conferência do Prof. Dr. Marcelo C. Rosa (UnB), \\ por ocasião da aula inaugural do Doutorado em \\ Ciências Sociais da Universidade Federal do \\ Espírito Santo.
}

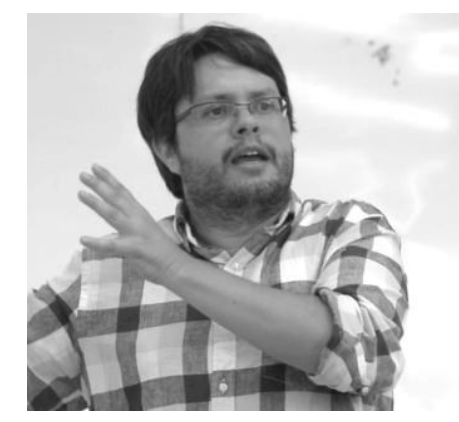

G ostaria de começar agradecendo o convite e dizer que vocês têm um desafio e tanto que marca as ciências sociais: como juntar três disciplinas com associações científicas diferentes, congressos diferentes, publicações diferentes, para produzir conhecimento juntas e formar mestrandos e doutorandos. Há uma outra agenda de longo prazo para um programa que está começando: o que definirá as ciências sociais em Vitória e na UFES? Que tipo de ciências sociais se fará aqui e por que vir estudar aqui? O que se aprenderá aqui que não se aprende em outros lugares? Algo que será discutido ao longo do tempo entre os professores e estudantes, certamente. Por isso, quero dar os parabéns pelo esforço de abrir o programa, agradecer novamente por me receberem, organizarem essa aula, e desejar boa sorte nos próximos anos, para que tudo isso venha culminar em 2023, já, provavelmente, com os primeiros doutores com títulos daqui. Então, boa sorte a vocês!

Agora, entrando no tema dessa aula inaugural - "Sociologias emergentes: uma agenda não exemplar" -, eu queria começar justificando o que é isso e de onde vem. "sociologias emergentes" foi um curso que criei na UnB, com outros colegas, há seis anos. Estávamos fazendo uma reforma no curso de graduação em ciências sociais e queríamos tornar o nosso curso mais contemporâneo, mais atrativo, mais interessante para quem estava ingressando na graduação. A ideia era trazer para os debates de teoria sociológica referências bibliográficas que não eram lidas em cursos obrigatórios. Durante muito tempo fui professor de sociologia contemporânea, tanto na Universidade Federal Fluminense (UFF) quanto na UnB. Em Brasília, tínhamos, no curriculum de sociologia, uma disciplina chamada de "Teorias clássicas", cuja ementa era Marx, Weber e 
Durkheim. Depois, havia o curso de sociologia contemporânea, em tese, com tudo que se fez entre 1920 e 2019! Então, tínhamos um semestre para três autores e, no semestre seguinte, um curso para 75 autores! Eu estou exagerando aqui, mas era muito difícil dar um curso de sociologia contemporânea realmente abrangente.

Eu confesso a vocês que quando comecei a dar aula de sociologia, há 15 anos, o que se chamava de sociologia contemporânea no Brasil eram teorias contemporâneas do meu avô! Aliás, meus avós nunca foram à universidade, nem meus pais, mas, se tivessem ido à universidade, teriam lido Habermas, Bourdieu e Giddens, que já estavam escrevendo naquele momento as teorias que lemos até hoje como contemporâneas.

Nós discutimos muito isso no Departamento de Sociologia da UnB, e a solução encontrada foi a proposição do nome "sociologias emergentes". Emergentes porque evocam textos que ganhavam protagonismos temáticos e/ou regionais, ou ainda textos que eram feitos por pessoas e em lugares não hegemônicos. Averiguamos que nos cursos obrigatórios de teoria sociológica líamos basicamente homens, brancos e europeus. Não havia uma única mulher nas bibliografias formais, assim como nos cursos obrigatórios em que estudei sociologia a vida inteira. O tema passou a ser uma preocupação de alguns professores. O mundo visto por homens brancos, europeus, existe, mas eles não são os únicos que veem o mundo. Como é que poderíamos lidar com isso? Queríamos criar um curso que desse conta desse problema. Como é que a gente vai lidar com um curso que "trabalha" com teoria, se queremos uma teoria que não seja feita exclusivamente por homens brancos e europeus dos anos 1960 ? O nome politicamente correto foi, então, "sociologias emergentes", teorias que emergem de vários lugares e pessoas.

Vou tomar uma área como exemplo: o chamado pensamento social brasileiro. Ao longo do tempo, foram estabelecidos cursos de pensamento social brasileiro em várias graduações. Cursos que não são chamados de teóricos, tampouco de metodológicos, sendo, na maior parte dos casos, estudos de história da sociologia brasileira. O ponto fundamental é que esses cursos propositalmente não desafiam ou ampliam os cânones das teorias sociológicas gerais que ensinamos, e tendem a ser usados para interpretar apenas o Brasil.

Existem teorias que o cânone da sociologia brasileira, com diplomacia, nomeia "pensamento social brasileiro", "teoria social latino-americana", "teorias feministas", mas no que isso muda o que fazemos como sociologia? Confesso que sou cético quanto ao potencial do que fazemos e ensinamos nas ciências sociais. Tendemos a ser muito diplomáticos ao reconhecermos que o que sabemos é limitado, mas o que fazemos para buscar uma ampliação? Na melhor das hipóteses, chamamos, como eu faço, esses e essas autores(as) para as

Caderno Eletrônico de Ciências Sociais, Vitória, v. 8, n. 1, pp. 136-148, 2020. 
"periferias" de nossa graduação e pós-graduação: as disciplinas optativas. No entanto, ainda não encontramos um modo para que essas teorias outras desafiem o centro do que fazemos. Ou seja, essa diplomacia tem nos permitido ter contato periférico ou temático com teorias feitas por mulheres, na África, na Índia, na América Latina, mas na hora de elaborar nossas aulas de teorias sociológicas, usamos quase sempre os homens europeus que já conhecemos. Assim, criamos alguns cursos de Pensamento Social de um ou outro lugar, ou de Teorias Feministas, por exemplo.

Em termos de movimentos emergentes, que certamente vocês já devem ter visto em seus cursos, parece haver duas características gerais que surgem contra o cânone ou para além do cânone que periferiza. Existem bons textos, que não são de agora, que criticam uma certa geopolítica euro-norte-americana nas ciências sociais. É importante lembrar que a teoria social ajuda a pensar, a enxergar, a descrever e a fazer o mundo. Querendo ou não, boa parte do que a gente faz é um uso normativo da teoria social. A gente vai, normalmente, ao mundo para testar o que o Giddens ou o que Bourdieu dizem nos textos que lemos, e acabamos vendo!

Pierre Bourdieu é o autor mais lido nas ciências sociais brasileiras, pelo menos é o mais citado há mais de duas décadas. Costumo ler frequentemente dissertações e teses que veem o habitus em tudo... porque se você vai procurar o habitus, tende a encontrá-lo sempre. E não à toa, Bourdieu escreve muito bem sobre isso, sobre o habitus e sobre o campo (seus conceitos-chave). Nossos professores em suas dedicadas aulas nos convenceram bem de como eles funcionam para falar do "social". O problema não está em Bourdieu e em seus conceitos, está na sociologia que a gente faz! Como a teoria se tornou uma ideia normativa, nós aprendemos que precisamos ver na realidade o que se aprendeu na teoria. Limitamo-nos a isso, deixando de ver outras coisas inusitadas porque não dispomos de teoria (conceitos) para interpretá-las. Tornamo-nos bons observadores da vida dos homens brancos e de suas ações que afetam os demais seres no mundo.

Nós, brasileiros, íamos a Paris aprender com Bourdieu, mas o que Bourdieu aprendia com a gente? Com cientistas sociais e com a realidade brasileira? Vocês talvez não sejam dessa geração, mas Bourdieu chegou a escrever, no final dos anos 1990, em seu período mais militante, um texto que foi usado contra a adoção de políticas de ações afirmativas no Brasil ${ }^{1}$. Ele e seu dileto estudante L. Wacquant afirmavam que o tema racial como foi adotado no Brasil era "imperialismo norte-americano". Não faria nenhum sentido ter ações

\footnotetext{
${ }^{1}$ BOURDIEU, Pierre; WACQUANT, Loïc. Sobre as artimanhas da razão imperialista. Estudos afro-asiáticos, 2002, 24.1, pp. 15-33.
}

Caderno Eletrônico de Ciências Sociais, Vitória, v. 8, n. 1, pp. 136-148, 2020. 
afirmativas nas universidades públicas no Brasil, porque os EUA é que têm cotas raciais em uma sociedade racialmente polarizada. Bourdieu, ao contrário de Wacquant, nunca tinha pisado aqui. O texto foi divulgado no começo das discussões das ações afirmativas - eu era aluno ainda - e foi muito utilizado para desmerecer as ações afirmativas nas universidades brasileiras entre cientistas sociais de esquerda. Afinal, as interpretações vinham do principal cânone vivo da sociologia nacional.

De novo, o problema não é Bourdieu e sua opinião política, mas sim ele falar por meio da sociologia de coisas, pessoas e lugares dos quais não tinha a menor ideia. A extensão do dilema é que as teorias canônicas e hegemônicas falam de coisas específicas, mas suas teses e conceitos se tornaram "universais" pelo modo como as ensinamos e utilizamos. A ideia das "sociologias emergentes" tem a ver com procurar coisas que ainda não existem nas teorias hegemônicas.

Nas "sociologias emergentes", no curso optativo que ofereço há cinco anos na graduação e na pós-graduação, tento dar atenção a duas coisas:

a) uma crítica da sociologia hegemônica, para mostrar os limites daquilo que fazemos como ciências sociais ou como sociologia;

b) sociologias que apresentam outras formas de existir e objetos não encontrados nas teorias hegemônicas.

No primeiro grupo, o foco tem se dado na "dependência acadêmica" das sociologias como a brasileira. O ponto de partida é que somos academicamente dependentes da Europa e dos EUA. Muitos professores da minha geração e das anteriores foram formados na Europa e nos EUA. Isso já era um problema porque demonstrava que o saber estava apenas "lá fora" e a pesquisa poderia ser feita por aqui mesmo. Os livros não chegavam aqui no Brasil com frequência, a internet não existia, então não tínhamos contato com a literatura mais recente. Íamos para fora a fim de ler coisas que nas bibliotecas brasileiras não havia. Líamos em inglês, francês, alemão, mas não havia acesso livre a livros importados aqui, de modo que se criava um movimento em que aquele que ambicionava a carreira acadêmica de sucesso tinha de ir para a Europa ou para os Estados Unidos. Hoje, graças à internet e a vários sites alternativos que distribuem conteúdos, conseguimos acessar muitas dessas coisas. $O$ acesso e a circulação da literatura são agora muito maiores, mas, se vocês prestarem atenção, vocês continuarão lendo Bourdieu, Habermas e Giddens nos cursos de formação, como literatura canônica.

Ainda assim, há um apelo da literatura sociológica pela "independência acadêmica", que ao longo de 40 anos tem exposto os limites dos cânones para lidar com casos que estão fora do mundo deles. Raewyn Connel, socióloga 
australiana, em seu livro Teoria do Sul², explicita isso. O sociólogo português Boaventura de Sousa Santos publica também a coletânea, com a socióloga moçambicana, Maria Paula Meneses, Epistemologia do Sul'. Essa ideia do "Sul" vem para lidar com isso: do "sul" são as referências que não são canônicas, pois nada que é do sul é canônico, e basicamente, se quisermos localizar o sul nas ciências sociais, seria basicamente tudo o que não é Europa (central) nem EUA.

Essa discussão do sul e das ciências sociais tem origem lá nos anos 1960. Vários autores debatem isso. O sociólogo mexicano Pablo Gonzáles Casanova ${ }^{4}$ vai discutir isso na América Latina. O sociólogo malaio Syed Hussein Alatas desenvolveu uma tese, nos anos 60, quando foi fazer doutorado na Holanda (assim como a Índia, a Malásia foi se tornar independente apenas na segunda metade do século $X X$ ), escrevendo sobre o sociólogo com a mente cativa, ou sobre o "cativeiro da mente" . Explicou que todo mundo era autorizado a "fazer sociologia" se usasse a mentalidade dos europeus e suas categorias classificatórias, portanto, se procurasse pelas coisas que havia nas teorias europeias ao olhar para a sua realidade. Ele problematiza os textos sobre religião de Max Weber. Nos textos de Weber, está lá a ética protestante, havia religião na China, na Índia, havia o judaísmo antigo. Weber faz uma referência enorme ao Oriente sem nunca ter feito uma pesquisa com pessoas de lá. Alatas mostra como a teoria weberiana ajudou a "complicar" a vida da sociologia malaia, porque é uma teoria da racionalização, da secularização e do desencantamento do mundo. Ele expõe com habilidade o que acontece com o mundo europeu (uma parte dele) e sua sociodiceia. Como ele ou outros sociólogos descreveriam a Malásia? Um país predominantemente muçulmano do mundo, onde mulçumanos fazem sociologia com religião.

S. H. Alatas discute em seus textos os limites das impressões de Weber. Mostra como a literatura sociológica malaia, que utilizava Marx, Weber, Durkheim e outros para descrever a Malásia, chegava à conclusão equivocada de que o país não se desenvolvia como os europeus porque tinha a religião como centro da vida. Alatas usava em sua tese de doutorado a expressão "O Mito do Nativo-

\footnotetext{
${ }^{2}$ CONNELL, Raewyn. Southern theory: The global dynamics of knowledge in social science. Allen \& Unwin, 2007.

3 MENESES, Maria Paula; SANTOS, Boaventura de Sousa. Epistemologias do sul. Coimbra: Almedina, 2010.

4 GONZÁLEZ CASANOVA, Pablo. Sociedad plural, colonialismo interno y desarrollo. América Latina, 1963, 6.3, pp.15-32.

${ }^{5}$ ALATAS, Syed Hussein. The Captive Mind In Development Studies. [Part 1]. International Social Sciences Journal, 1972, 24.1, pp. 9-25.
}

Caderno Eletrônico de Ciências Sociais, Vitória, v. 8, n. 1, pp. 136-148, 2020. 
Vagabundo"6 para descrever esse dilema. Ele fez uma interessante discussão crítica com Weber, de maneira a mostrar que se você só ensina Weber, seus alunos só vão medir as coisas de acordo com o que ele prescreve. Se pegarmos uma boa parte do pensamento social brasileiro, as coisas também caminham por aí, para mostrar as coisas que nos faltam, e nos faltam para ser como a teoria nos diz que temos de ser.

Eu confesso que depois de ensinar a sociologia por 15 anos, estou farto de descrever o mundo assim. Mas eu tenho emprego, ganho salário, sou convidado pra vir aqui... e sei que somos avaliados por saber os cânones. Eu fiz concursos públicos para professor (uns cinco ou seis na vida), nem em todos eu passei, mas sempre tive de dar aula sobre Marx, Weber ou Durkheim. De novo, o problema do Weber não é do Weber ou do Durkheim ou do Marx. O problema é que a gente só sabe o que eles nos prescrevem. A ideia dos "emergentes" é tentar lidar com isso e incorporar mais possibilidades no que a gente já sabe.

Há várias fontes bibliográficas alternativas. Mais recentemente (há mais de 20 anos), um cientista social do Benin chamado Paulin Hountondji ${ }^{7}$ trabalha com a ideia de "endogenização", que seriam formas de "traduzir criticamente" as teorias hegemônicas para nossos lugares de pesquisa. Na América Latina, já citei o Pablo Gonzáles Casanova, que está vivo, com mais de 90 anos. Ele reescreveu muito recentemente um texto de como as ciências sociais também podem reproduzir o que ele chamou, lá nos anos 60 , de "colonialismo interno" 8 , porque nós acabamos copiando as categorias europeias e norte-americanas com que nos descrevem.

Essas categorias produziram um continuum no tempo/espaço, no qual as coisas que hoje chamamos de Brasil só entram depois de 1.500 anos, como se nada existisse antes. Pablo Gonçalves Casanova falava, nos anos 1960, em como a elite intelectual mexicana e todas as elites intelectuais latino-americanos são brancas, e aí há outro dilema: a ideia de que a América Latina não é um continente de brancos. O Brasil, felizmente e oficialmente, deixou de ser um país branco nas últimas duas décadas, segundo o censo, só que a mentalidade de quem dirige o país, em vários sentidos (em nosso caso, intelectualmente), continua sendo branca, e foi isso que Gonzáles Casanova chamou de "colonialismo interno". Os brancos ocupam posições-chave, escolhem e filtram o que vai ser ensinado, o que vai ser pensado e quem vai ser beneficiado por

\footnotetext{
${ }^{6}$ ALATAS, Syed Hussein. The Myth of the Lazy Native: A Study of the Image of the Malays, Filipinos and Javanese from the 16th to the 20th Century and Its Function in the Ideology of Colonial Capitalism. Routledge, 2013.

7 HOUNTONDJI, Paulin J. (ed.). Endogenous knowledge: Research trails. African Books Collective, 1997.

${ }^{8}$ CASANOVA, Pablo González. Colonialismo interno (uma redefinição). BORON, AA; AMADO, J.; GONZÁLEZ (Org.). A teoria marxista hoje: problemas e perspectivas. Buenos Aires: CLACSO, 2006, pp. 395-420.
}

Caderno Eletrônico de Ciências Sociais, Vitória, v. 8, n. 1, pp. 136-148, 2020. 
isso, obviamente. É um dilema muito interessante na América Latina que o branco aqui não seja visto como estrangeiro. Em outros lugares, na África do Sul, onde faço pesquisa, quem é branco é sempre estrangeiro, mesmo quem está há três, quatro, cinco gerações por lá.

Outra crítica mais recente que se faz é ao modo colonial de se fazer sociologia e ciências sociais e ao seu "império classificatório", que colonizou as mentes de cientistas. Catherine Walsh, pesquisadora americana ligada ao grupo que debate a colonialidade do saber, reflete sobre os limites dessa classificação ${ }^{9}$. Prestem atenção que eu não falei aqui da Catherine Walsh por acaso, pois quantas mulheres decoloniais a gente lê por aí? Os autores e autoras decoloniais que a gente mais cita são indígenas da América Latina? Não, são quase todos homens brancos como eu.

Uma das coisas que eu tenho tentado pensar é como fazer pesquisa com a crítica dos chamados decoloniais. Uma coisa é a gente saber que nossas categorias são limitadas, já disse, mas como é que a gente faz pesquisa diferente sabendo disso? Todo mundo que está aqui e dá aula na sociologia brasileira faz pesquisa! A questão é: como você utiliza essa crítica para fazer pesquisa? Nas ciências sociais, ainda não vejo uma agenda clara de como a gente fará pesquisa com a crítica pós-colonial e decolonial. É importante saber que Weber não explica tudo, que Marx tem limites, que Bourdieu tem limites nisso e naquilo, mas como é que a gente faz pesquisa para além deles?

Isso tem me preocupado bastante. Citarei alguns exemplos de como tento lidar com esses dilemas nos meus cursos. Há alguma literatura já em português, especialmente para as pessoas da graduação, com propostas metodológicas interessantes. Toda teoria social tem método. Teoria e método caminham mais ou menos juntos, e o dilema é que para mudarmos ou ampliarmos a teoria, a gente também tem de pensar em outros métodos, outros modos de fazer pesquisa. É complicado se a gente continuar fazendo pesquisa sempre da mesma forma. Um exemplo clássico é aplicar questionários de pesquisa (surveys): você faz sempre as mesmas perguntas e pouco importa para quê. Isso não muda a teoria que informou seu projeto de pesquisa. Para mudar, você deve ter outro modo de fazer as perguntas. Uma boa pesquisa levará a perguntas cujas respostas devem testar os elementos teóricos das ciências sociais. Mas não se faz isso numa pesquisa quantitativa, por exemplo.

Passo agora àquelas sociologias que tentam produzir e trabalhar com outro modos de existir.

\footnotetext{
9 WALSH, Catherine. ¿Son posibles unas ciencias sociales/culturales otras? Reflexiones en torno a las epistemologías decoloniales. Nómadas (Col), 2007, 26, pp. 102-113.
}

Caderno Eletrônico de Ciências Sociais, Vitória, v. 8, n. 1, pp. 136-148, 2020. 
Há muitos outros modos de fazer e pensar as ciências sociais, movimentos interessantes como, por exemplo, o movimento das "sociologias indígenas". Alguém aqui já leu alguma coisa sobre isso? Pela falta de reação do público, ninguém leu! "sociologia indígena" é um movimento que se criou dentro da Associação Internacional de Sociologia (ISA), na década de 80, para falar da África e da cultura da África. Foi o jeito de incluir a África nas teorias sociais. No grupo de teoria social da Associação Internacional de Sociologia, nos congressos mundiais, criou-se uma seção para se falar de "sociologias indígenas", que seriam teorias feitas para se falar de modos de existir africanos. Alguns sociólogos africanos (na época, todos homens), especialmente o nigeriano Akinsola Akiwowo ${ }^{10}$, desenvolveram uma teoria a partir da poesia iorubá, e essa teoria foi debatida durante vinte e poucos anos na Associação Internacional de Sociologia (acabei de escrever um texto sobre isso) ${ }^{11}$. O problema da "sociologia indígena", que era a sociologia africana para o Ocidente, era que nem na Nigéria era lida quando foi produzida. Lá se liam também os clássicos que conhecemos por aqui. Ela foi feita por cientistas sociais africanos para uma audiência internacional aberta ao diálogo com a África.

As sociologias indígenas (africanas), nos anos 80 , foram uma sociologia da poesia oral e da tradição oral iorubá, para pensar uma ideia de sociedade. Mas qual o problema desta iniciativa? Uma socióloga contemporânea, que defende a importância das teorias do sul por exemplo, afirma que a fonte oral não pode ser objeto da sociologia porque ela não é exata e confiável. O conhecimento oral muda: cada um que conta a história, conta de um jeito diferente e, realmente, a tradição iorubá vai mudando ao longo da história. Por isso, a oralidade é uma coisa com que a teoria social lida muito mal. O dilema da oralidade é que ela muda e que não dá para ter um conceito que explique a ação, por exemplo. Se você tem um conceito fixo, ele deixa de ser oral e passa a ser escrito, e isso se complica. Só que não dá para fazer "sociologia indígena", nigeriana, com a mentalidade de quem nunca viveu em um mundo social não conceitual.

Outro bom exemplo é um grupo mais conhecido como estudos subalternos da Índia. Acho que todo mundo aqui já ouviu falar da Gayatri Spivak, que se tornou a representante mais famosa no Brasil desse grupo. Mas ela entrou muito tarde para ele e, na verdade, era uma crítica dos estudos subalternos indianos originais. Ela se insere a partir da crítica ao fato de que o grupo não tinha autoras e vozes de mulheres. No clássico livro dela, Pode o subalterno

\footnotetext{
${ }^{10}$ AKIWOWO, Akinsola A. Contributions to the sociology of knowledge from an African oral poetry. International Sociology, 1986, 1.4, pp. 343-358.

${ }^{11}$ ROSA, Marcelo C. Sociologias indígenas ioruba: a África, o desconcerto e ontologias na sociologia contemporânea. Estudos Históricos (Rio de Janeiro), 2019, 32.67, pp. 389-408.
}

Caderno Eletrônico de Ciências Sociais, Vitória, v. 8, n. 1, pp. 136-148, 2020. 
falar?, ela trata do Sati, o sacrifício das viúvas, e de como se fazia apenas a leitura ocidental e colonial das mulheres indianas e da dominação de gênero. Spivak, então, faz uma pesquisa para mostrar que se criou uma leitura etnocêntrica sobre as mulheres indianas, de que elas eram mais vítimas do patriarcado do que as mulheres ocidentais seriam. Isso porque o mundo ocidental enxerga predominantemente as mulheres como dependentes e vítimas dos homens ${ }^{12}$.

É interessante que os "estudos subalternos" da Índia tinham uma inspiração quanto às fontes de pesquisa na historiografia britânica, de Edward Thompson, que, para discutir o movimento operário inglês, estudava a vida cotidiana dos trabalhadores. Mas eles vão além disso porque trazem o dilema de que, na Índia, os subalternos, mais especialmente as mulheres, não têm fontes escritas. Não se encontram documentos em cartório, não se encontra imprensa que fale desses grupos e, quando fala, fala "em nome" desses grupos. Precisava-se, então, de um modo de ampliar o que se sabia sobre o mundo ali, para se lidar com a realidade. Eles criaram uma tradição, ainda muito pouco vista no Brasil, até onde eu sei, sobre as metodologias que precisam ser desenvolvidas para se fazer uma teoria acerca da vida desse subalterno e, de novo, para não medir a vida do subalterno na relação com a vida do dominante. Esse é o problema clássico para o qual Spivak chamou atenção: "pode o subalterno falar?". E a resposta dela é outra pergunta: "quem ouve o subalterno?". No fundo, ninguém ouve, porque a gente não tem ouvidos para isso; a gente está procurando saber do subalterno em outros documentos, ou se vai ao subalterno com perguntas que você faria para si mesmo, tendo como parâmetro da vida desse subalterno a vida do dominante, sempre. Mudando o foco da atenção, porém, os estudos subalternos indianos levaram ao desenvolvimento de outras narrativas teóricas fundamentais sobre o Estado, sobre a democracia, que a gente não lê aqui. A maioria delas é voltada para a própria Índia, algumas para a África, mas, no Brasil, quase não se veem esses estudos. Quando muito, viraram "estudos culturais", mas não entram de verdade nas ciências sociais brasileiras.

Nas "sociologias não-exemplares", há ainda um grupo para o qual eu queria chamar atenção, chamado aqui de "feminismo de terceiro mundo". Vejam, eu faço pesquisa de campo sobre movimentos que lutam por terra, sem terras, na África do Sul. Essa é a pesquisa que eu faço já há 14 anos. Há algum tempo, eu estava participando de um desses debates, estava discutindo sobre teoria social com colegas de universidades africanas e usei esse argumento: "- Olha, nenhuma teoria que a gente faz aqui 'toca' nas teorias que a gente ensina. Nada mudou nenhuma teoria social. As teorias subalternas, decoloniais e todos

12 MOHANTY, Chandra Talpade. Under Western eyes: Feminist scholarship and colonial discourses. Boundary 2, 1984, pp. 333-358.

Caderno Eletrônico de Ciências Sociais, Vitória, v. 8, n. 1, pp. 136-148, 2020. 
esses movimentos sociais, de origens indígenas e africanas que lemos, nada disso mudou a teoria social ou sociológica". Foi nesta situação que uma colega da Universidade de Dar Es Salaam, Marjorie Mbiliniyi, me chamou atenção: "Você, então, não leu as teorias feministas!". Foi nesse momento que eu me dei conta, por acaso, de que eu já havia lido algumas dessas teorias feministas, e a colega foi me mostrando que, dentro da teoria feminista, houve um debate já nos anos 1970 de que as mulheres não-europeias e não-brancas não são iguais às mulheres brancas do Norte, e que uma coisa fundamental era que a experiência delas (mulheres europeias e americanas) não poderia servir para medir o que é ser mulher. Por isso, há uma série de autoras que eu conhecia muito pouco e acabei incorporando ao meu curso mais recentemente. Aliás, uma parte do compromisso do meu departamento com a oferta desse curso de "sociologias emergentes" é que metade da bibliografia tem de ser escrita por mulheres. Temos uma série de autoras, as chamadas também de "chicanas", na fronteira dos Estados Unidos com o México. São diversas autoras que não fazem parte do mesmo movimento.

Eu queria ainda citar Oyeronke Oyewumy, uma autora nigeriana que eu conheci na UnB há uns dois anos, em um evento. Fiquei fascinado pelas coisas que ela escrevia porque ela discutia com essas sociologias indígenas e iorubá para mostrar como foram feitas por homens iorubás e não por mulheres. Ela faz um debate interessantíssimo sobre a "invenção da mulher pelo Ocidente" e os impactos que isso tem nas mulheres do "terceiro mundo", que nunca eram "mulheres de verdade", "porque elas são sempre piores do que as mulheres do Ocidente". Ela faz uma discussão muito densa de como isso complica literalmente o reconhecimento de que existiam quaisquer movimentos políticos de mulheres que não fossem os movimentos políticos de mulheres ocidentais, como se o movimento feminista só pudesse ser traduzido pelas categorias nas mulheres ocidentais. Há vários livros interessantes dela e todos eles circulam de graça pela internet, mas saiu um livro organizado pelo professor Joaze Bernardino ${ }^{13}$, do meu departamento na UnB, que tem um texto dela, em que ela lida justamente com esses limites da teoria feminista. Assim, dentro da teoria feminista, também as feministas não brancas norte-americanas se sentiram um tanto quanto "incomodadas" pela hegemonia branca.

Chela Sandoval ${ }^{14}$ criou um uma metodologia chamada "metodologia dos oprimidos" para falar das mulheres não brancas e desenvolveu um tipo de metodologia diferente, cuja leitura eu recomendo. E quase ninguém fala que o Walter Mignolo "usurpa" (no sentido de ficar com o reconhecimento do uso do

13 BERNARDino-COSTA, Joaze; MALDONADO-TORRES, Nelson; GROSFOGUEL, Ramón. Decolonialidade e pensamento afrodiaspórico. Autêntica, 2018.

${ }^{14}$ SANDOVAL, Chela. Methodology of the Oppressed. University of Minnesota Press, 2013.

Caderno Eletrônico de Ciências Sociais, Vitória, v. 8, n. 1, pp. 136-148, 2020. 
termo) a ideia de "fronteira" de Gloria Anzaldúa" ${ }^{15}$. Ela, ainda nos anos 80, desenvolve a ideia de "fronteira", "fronteira de gênero", porque não são mulheres no sentido binário clássico do termo, são mulheres que se relacionam com mulheres, que vivem na fronteira entre México e Estados Unidos, e também não são brancas. Então, nos debates feministas, parece que se avançou um pouquinho, mas o problema maior é se a gente considera que a teoria feminista é teoria social, seja na antropologia, seja na ciência política ou na sociologia. Eu quase nunca vi as teóricas feministas adentrando os cursos obrigatórios de teorias. Se vocês souberem, me avisem. Elas normalmente vão entrar em cursos sobre feminismo, sobre teorias feministas, mas elas raramente entram em curso de teoria, raramente ocupam o centro do que a gente faz.

É muito legal poder estar aqui hoje falando das coisas que eu faço no meu grupo de pesquisa, que, na verdade, começou lá na Universidade Federal Fluminense, e ainda se chama "Laboratório de Sociologia Não-Exemplar". Eu trabalho com os meus alunos e com as minhas alunas do seguinte modo: "Você quer fazer pesquisa de alguma coisa, mas se você tiver um conceito para descrever a coisa, tem outros professores para ajudá-lo(a)". Eu gosto de orientar coisas que não podem ser definidas pelos conceitos que a gente já tem e que não alcançam as coisas que a gente tem feito e que a gente ainda tem dúvidas de como classificar. Minha orientação pessoal é que meus alunos não classifiquem em lugar nenhum, que não procurem um escaninho para encaixar as coisas.

A nossa formação é assim: a gente tem professores, eu vou para a sala ensinar os alunos a botarem as coisas em escaninhos, isso é isso, aquilo é aquilo, isso aqui é "feminista", isso aqui é "democracia", e o Brasil não cabe bem nessas coisas, a gente sempre fica na margem. Mas o ponto é esse. Não-exemplar é lidar com duas coisas fundamentais: inspirado nessa crítica teórica, admitir o nosso lugar e os limites da sociologia e das ciências sociais que fazemos. Ninguém nunca faz uma pesquisa para dizer assim: "- Olha, eu só fiz seis perguntas e eu só posso dizer isso". A gente faz as seis perguntas e fala de "democracia". Esse é o jeito de falar na ciência, universalmente. Além da crítica aos limites - o conhecimento vai ser sempre limitado -, o "não-exemplar" traz uma ideia de expansão do que a gente faz. Eu tenho chamado para isso não só autores e autoras não hegemônicos, mas penso na expansão ontológica ou expansão de existências que a gente ainda não consegue nas teorias convencionais. Estava conversando com os colegas do PGCS-UFES hoje de manhã: a gente sabe qual é a população da Índia? Um bilhão e trezentos milhões de pessoas; na China, um bilhão e quatrocentos; na África, um bilhão e

${ }^{15}$ ANZALDÚA, Gloria, et al. Borderlands: la frontera. San Francisco: Aunt Lute, 1987.

Caderno Eletrônico de Ciências Sociais, Vitória, v. 8, n. 1, pp. 136-148, 2020. 
trezentos. Isso é $60 \%$ da população do mundo. A gente faz sociologia ignorando o que se faz de sociologia para essa maioria do mundo. A minha questão não é dizer que a teoria do capitalismo ou da modernidade está errada, mas afirmar que ela não fala do mundo inteiro.

Como comentei antes, comecei pesquisando o MST no Brasil. Depois, cheguei à África do Sul muito entusiasmado e procurando um novo objeto de estudo. Eu me ofereci para ser tradutor porque os militantes do MST que foram para lá não falavam inglês. Na África do Sul, na primeira reunião com os militantes do MST e os militantes sul-africanos, a primeira pergunta do militante sul-africano foi: "- Vem cá, por que tem 'sem-terra' branco no Brasil? Porque aqui na África, os brancos vieram e roubaram a nossa terra. No Brasil, não foi assim?". Eu conto essa memória porque nos 12 anos em que eu pesquisei "sem-terra" no Brasil, eu nunca tinha pensado que o MST era um movimento ideologicamente de camponeses, que é uma categoria clássica do Ocidente branco, tanto que quando a gente fala de movimentos indígenas ou movimentos quilombolas, a gente não os classifica entre os "sem-terra". Pela primeira vez, me dei conta também de que a "existência" na terra, no caso africano, não era delimitada pela agricultura comercial, como era o caso do MST. Eu sabia como as coisas eram e que, no Brasil, havia comunidades tradicionais. Mas quem disse que 0 que define o uso e o sentido da terra é a agricultura? Então, desde lá, eu tenho trabalhado com isso, tenho sofrido para lidar com isso, com essas questões.

O ponto que tem de ficar mais ou menos marcado é: "- O que eu faço para pensar tudo que não é exemplar? Como desenvolver categorias novas para falar com essas pessoas?". Não adianta falar que quilombola não é "sem-terra", mas como é que eu vou explicar "quilombola" e dizer para alguém da África que essa é a categoria para a população negra? Há uma relação com o mundo que não é só com a cor - é com a terra, com o espaço. Eu ainda não vi as nossas teorias darem conta disso, talvez porque a gente tenha categorias muito ocidentais, ou ocidente-centradas, para descrever quem são essas pessoas, negros, brancos e indígenas, mais ou menos como eu aprendia na escola como a população brasileira se dividia. Mas as categorias não são universais. O universal só é universal porque tem poder e força, então, tudo aquilo que a gente acha que é universal não o é porque tem mais pessoas no mundo, mas é porque elas tiveram mais força para se impor como categoria de verdade. Vocês têm ideia da população rural do mundo? A urbana só se tornou maior há seis anos. Só que faz 40 anos que a sociologia diz que o mundo é um mundo industrial e isso é o que importa. A sociologia rural parou de existir no Brasil, de verdade, como disciplina autônoma há 30 anos. Porém, são quatro bilhões de pessoas no mundo que vivem da terra e na terra, e a gente não consegue lidar com isso, assim como a maioria da população do mundo não é de homens e a gente fala

Caderno Eletrônico de Ciências Sociais, Vitória, v. 8, n. 1, pp. 136-148, 2020.. 
como se fosse, não é de branco e a gente fala como se fosse, não é de ocidentais e a gente fala como se fosse.

Para concluir, o ponto aqui não é fazer uma contraposição com a sociologia que a gente conhece e dizer que ela não serve para nada. O desafio que eu coloco para este Programa, com um doutorado que se inaugura agora, para os doutores que começam a ser formados agora, é para onde a gente vai expandir o conhecimento e como podemos introduzir o desconhecido, o inesperado, como algo que seja impulso para a pesquisa. Em geral, aquilo que a gente não identifica, a gente tende a descartar, porque não tem quem oriente, não cabe no projeto, não tem literatura para lidar com aquilo. Mas este é o meu ponto: como criar? Eu não tenho nenhum problema em reproduzir categorias como "camponeses", "proletários", "democracia"..., mas, para além de reproduzir, a ideia de fazer ciências sociais e fazer pensamento social é, para mim, fazer pesquisa ontoformativa. Contribuir para a inclusão de novas existências e para pensar novos modos de existir para as ciências sociais e, também, para as políticas públicas, para outros lugares, onde as existências que há hoje não aparecem. Nessa ideia de ontonormatividade, o ideal seria não dizer o que é mais democracia e o que é menos democracia, quando a gente não precisar mais fazer isso. A gente pode partir para descrever coisas que ainda não foram descritas, novas existências, e criar novas teorias. A única forma de se contrapor às teorias exemplares não é dizendo que elas são limitadas. O desafio é formar novas categorias a partir daí, só que provavelmente não estarei vivo para ver isso no Brasil, pois demandará algum tempo. Mas certamente será uma agenda bem interessante para as ciências sociais.

\section{Fim da conferência}

\section{Transcrição:}

Glendo da Silva Nascimento - Bacharel em Ciências Sociais - UFES.

\section{$1^{a}$ revisão-edição:}

Adelia Miglievich-Ribeiro - Professora do Departamento de Ciências Sociais da UFES. 